\title{
ENQUETE
}

\section{BØN SOM VINDUE}

\author{
SIDSEL MARIE
}

I mit arbejde med de esoteriske, mystiske dimensioner af den russiske østortodokse kristendom er jeg ofte stødt på en skepsis fra uindviede, der dømmer den private og kontemplative religiøse praksis som antisocial, udelukkende egen-nyttende og dermed uetisk. Formålet med nærværende skrift er at diskutere denne doms gyldighed gennem en todelt refleksion over forholdet mellem bøn og etik.

Indledningsvis vil jeg præsentere en for mange måske ubekendt mystisk, østortodoks kristen bønstradition ved navn „hesykasme“. ${ }^{1}$ Jeg vil vise, hvorledes denne traditions særegne bønspraksis indeholder en afgørende dydsetisk dimension, der betoner karakteropbyggelse. Denne ide læner sig op ad en nyere retning i religionsantropologi, som netop ser bøn som et led i etisk livsførelse og moralsystemer hos tænkningstraditioner, hvor bøn indtager en central placering (se fx Asad 1993; Mahmood 2001; Robbins 2004; Henkel 2005; Naumescu 2012; Bandak 2017; Luehrmann 2017). Flere af disse arbejder tager afsæt i den sene Michel Foucaults ideer om selvets teknologier (1988), hvor subjekters aktive kultivering af en særlig etisk relation til selvet og verden er et centralt omdrejningspunkt (se også Foucault 1990, 1997). Jeg vil tage udgangspunkt i hesykasmen og foreslå, at dennes bønsform giver anledning til en praksisorienteret og oplevelsesbaseret etik hos den bedende, og at den hesykastiske etik herved udtrykker en yderliggående gennemførelse af den individbaserede soteriologisk motiverede etik i ortodoks kristendom mere bredt. Slutteligt vil jeg udvide min refleksion over bøn som et muligt tyngdepunkt i den bedendes etiske liv ved at sammenstille den hesykastiske bønspraksis med stoisk og zarathustriansk bøn, hvor karakteropbyggelse og selverkendelse ligeledes påskønnes. 


\section{Hesykasmen og hesykastisk bønspraksis}

Vi kan spore hesykastiske ideer og bønspraksis helt tilbage til det 4. århundredes kristne anakoreter, de såkaldte ørkenfædre, der udvandrede til den egyptiske og syriske ørken for her at hengive sig til et liv i bøn og askese i forsøget på at modtage Guds nåde. Der skulle imidlertid gå et årtusinde, før hesykasmen i det senbyzantinske rige officielt blev anerkendt som en særegen forgrening af den østlige ortodokse teologi og dermed for alvor slog rod i både gejstlig og menig bevidsthed (Strezova 2014). Efter et par hundrede års dvale, hvor hesykasmen primært levede blandt munke og eremitter, indtraf endnu en hesykastisk vækkelse; denne gang i det prærevolutionære Rusland. ${ }^{2}$ I dag udfolder traditionen sig primært blandt det årtusinde gamle og relativt uforstyrrede munkefællesskab på Athosbjerget i det nordlige Grækenland, hvor hesykastisk praksis og teologi har været stærkt forankret siden senbyzantinsk tid. I løbet af de seneste to årtier har den østkristne mystik dog også langsomt vundet indpas udenfor Athos-klostrenes mure - særligt i Rumænien, Bulgarien, Serbien og Rusland - hvor hesykasmen har manifesteret sig i både religiøs og spirituel praksis samt som neopatristisk politisk ideologi (Payne 2011; Petcu 2016).

Hesykasmen kan bredt betegnes som en esoterisk forgrening af den østlige ortodokse kristendom, der betoner den enkeltes vej til dennesidig forening med det hellige gennem asketisk, ensom livsførelse samt bestandig kontemplation af Guds væsen opnået ved uafbrudt bøn (Meyendorff \& Meyendorff 1974:iii-iv; Gavrilyuk 2013). På samme måde som i den mere generelle ortodokse kristendom er målet for den hesykastiske praksis at vokse til lighed med Gud og igennem deltagelse i det guddommelige at finde frelse. Det, der afholder mennesket fra denne guddommeliggørelse, er både moralsk fordærv, uregulerede lastefulde drifter samt menneskets tilbøjelighed til at miste sin angrende og bønfaldende rettethed mod Guds tilstedeværelse. Kroppen, sjælen og intellektets distraherende passioner og laster såsom ignorance, grådighed, vrede, stolthed, glemsomhed, frivolitet og dovenskab bliver således barrierer for åndelig udvikling og frelse. I hesykasmen udgør bønnen det primære værktøj til både bekæmpelse af disse laster, frigørelse fra verdslige distraheringer og rumination samt kultivering af dyb meditation på Gud. Bønnen indtager altså en helt central plads i hesykastisk soteriologi, idet det er ved hjælp af bøn, at den praktiserende kan bevæge sig gennem de tre stadier, der kendetegner spirituel udvikling i hesykastisk teologi: renselse (katarsis), erkendelse (theoria) og guddommeliggørelse (theosis). Gennem kontemplativ og vedholdende bønsrecitation nærmer den bedende sig Gud ved først at rense sindet og sjælen fra overflødige tanker, drifter, begær og al lidenskab, der ikke har Gud som sit objekt (gennemgå katarsis). Dette tillader herefter den praktiserende at tilegne sig theoria - ren kontemplation og fuld oplysning af 
Guds væsen og skabelsesværk - for til slut at opnå enhedsoplevelse, theosis, hvor skellet mellem den bedende og Gud ophører (Ware 2011:299-301). Den hesykastiske bønspraksis kan derfor karakteriseres som en apofatisk fordybelsespraksis, idet den bedende ved hjælp af bøn forsøger at eliminere al mental aktivitet associeret med forestillinger, emotioner og tankestrømninger (Ware 1986 [1979]: 163-64). Heraf følger det, at hesykastisk bøn ikke er videre oplagt som fællesbøn i den kollektive andagt. Den bedes fortrinsvis i ensomhed, hvor den praktiserende kan forsvinde ind i fuld introspektion. Derudover er det karakteristisk for den hesykastiske bønstradition, at bøn ikke forbeholdes kirkegang eller fastlagte klokkeslæt. Idet idealet for den praktiserende er at forblive i uafbrudt meditation på Guds verdslige tilstedeværelse, stiler hun efter konstant at være i bøn.

Den mest benyttede bøn til denne uafladelige bønspraksis er jesusbønnen, også kendt som hjertebønnen, hvis ordlyd almindeligvis er: „Jesus Kristus, Guds søn - forbarm dig over mig, en synder" ${ }^{3}$ Bønnen reciteres i takt med vejrtrækningen, mens den bedende bestræber sig på at flytte recitationens udspring fra stemmebåndet og talen, forbi intellektet og tanken til hjertet, hvorfra jesusbønnen gentages dybfølt og ustandseligt for at fiksere en bestandig rettethed mod Gud. Der er altså ikke tale om en ikke-involveret fremsigelse af et tomt mantra. Tværtimod består den ideelle bønsrecitation i hesykasmen i et fuldkomment, dedikeret engagement af hele den bedendes krop og sjæl med henblik på disses udvikling.

I den mystisk-kristne, hesykastiske antologi, Philokaliaen, finder vi flere steder udførlig vejledning til opøvelsen af en sådan bønspraksis (eksempelvis Munken Nikiphoros:192-206; Evagrius Eneboeren:53-72). Dette hænger sammen med værkets overvejende vægt på personlige, indre dimensioner af den religiøse oplevelse fremfor systematiserede, ritualiserede eller på anden måde institutionaliserede overbevisninger og praksisser. Philokaliaen adskiller sig sådan fra andre kristne tekstsamlinger som følge af dens betydelige fokus på en ikke-paradisisk, men nutidigt forankret radikal transformation og oplysning af den enkelte gennem oplevelsesbaseret indsigt $i$ og viden om det helliges natur. Teksterne $i$ antologien påskønner deltagelse via guddommeliggørelse som forudsætning for at få kendskab til det hellige; en deltagelse, der først og fremmest beror på, at den praktiserende transformerer sit eget selv for at kunne imitere Guds moralske ophøjethed. Gud kan i denne forstand hverken nås gennem metafysisk spekulation eller kollektiv gudsdyrkelse, og frelse kan ikke findes ved lejlighedsvis bønspraksis eller uengageret moralsk doktrinfølgen. Tværtimod må den enkelte begive sig ud på sin egen bønsbelagte sti af omfattende åndelig udvikling mod fuld moralsk mimesis i søgen efter frelse og sammensmeltning med det hellige. 


\section{Bøn som vindue}

Hvor den nyere antropologiske litteratur har vist mange eksempler på, hvordan bøn bør ses som en etisk praksis, vil jeg skubbe denne samtale videre ved at spekulere over, hvorvidt bøn også kan bruges som et vindue og endda en komparativ ramme til at undersøge etikkens divergerende udformninger i forskellige religiøse traditioner.

For at gøre dette må vi genbesøge enquetens første afsnit omkring hesykasmens grundaspekter. Her fremskrev jeg, at hesykasmen er en tradition karakteriseret ved en påskønnelse af den enkeltes mystiske oplevelse af mødet med Gud. Denne generelle tilbøjelighed i hesykasmen til at betone den enkeltes religiøse udvikling og oplevelse giver nemlig anledning til en særlig etisk diskurs, hvor individets etiske udfoldelse ligeledes er i centrum. Dette ser vi blandt andet ved et generelt fravær af delte moralske adfærdskoder i de hesykastiske skrifter (Horujy 2019:42, 54). I foucauldiansk terminologi kan vi sige, at etikken, forstået som intentionel selv-skabelse, spiller hovedrollen for hesykasmens moralsystem, mens de ordinerende normer for korrekt opførsel nøjes med at indtage en birolle. Det hesykastiske mål for den etiske praksis, theosis, kan ikke tilegnes ved blind efterlevelse af systematiserede moralske principper; det kræver en dedikeret etisk livsførelse, der må kultiveres af hvert enkelt subjekt gennem dedikeret bønspraksis.

Penduleringen mellem de eksterne koder for passende moralsk adfærd og subjektets interaktion hermed i form af selv-forandring har desuden en særlig frekvens i det hesykastiske moral system. Den etisk betonede selv-transformation er en evindelig bestræbelse, idet den søgte guddommeliggørelse kræver en radikal forsagelse af selvet, hvor den bedende konstant må være vågen for ikke at tabe Gud som det primære opmærksomhedsobjekt. For at opnå en moralsk renhed, der reflekterer Guds væsen, er det ikke tilstrækkeligt lejlighedsvist at søge aflad eller halvhjertet at følge moralske doktriner (Gregory Palamas:343-45). At akkvirere theosis kræver, at den praktiserende engagerer hele sit væsen og kultiverer indre askese ved at vogte sindet og rense sjælen gennem uafladelig gentagelse af jesusbønnen (Demacopoulos 2013:273; Horujy 2019:49). Subjektets etiske praksis i det hesykastiske moralsystem kan altså forstås som en kontinuerlig, uendelig bestræbelse: På samme måde som jesusbønnen reciteres til uendelighed, må subjektets etiske selv-transformation ustandseligt reaktualiseres. Denne særegne, ustoppelige bønspraksis kan endvidere bruges som vindue til at belyse, hvordan den hesykastiske etik placerer sig i forhold til kristen-ortodoks etik mere bredt. Åndelig udvikling hos den hesykastiske novice påbegyndes gennem fuld dedikation til konstant bøn og kompromisløs træning af sind og krop ud fra den overbevisning, at forening med det hellige kræver ustandselig årvågenhed. Det er 
svært at forestille sig en sådan praksis sameksistere med den almene ortodokse kristnes verdslige dagligdag fyldt med praktiske, familie- og samfundsmæssige forpligtelser, og den hesykastiske bønsmedierede etiske praksis kan derfor anskues som en vidtdrevet udførelse af den ortodokse kristendoms etiske påbud om den enkeltes indadskuende pilgrimsfærd mod frelse. Med andre ord kan den hesykastiske etik ses som en indre etisk komponent af en større, koncentrisk opbygget etik tilhørende den ortodokse kirke.

Ved at bruge bønnen som indgang til at forstå hesykasmens moralsystem kan vi således udpensle nogle væsentlige aspekter, herunder hvordan dette system og de teologiske refleksioner, som det opererer med, henstiller til og peger os i retning af en oplevelsesbaseret, praksisorienteret, ustandselig og dydsetisk fokusering. Vi kan altså bruge bøn som et metodisk greb til at tilgå den partikulære moralstruktur i hesykasmen. Mens bøn kan agere vindue til at forstå adskillige dimensioner hos den respektive tænkningstradition, det være sig eksempelvis dens sociale dynamikker, kosmologi og værdisystem, synes bøn at være særligt egnet til at belyse etik. Dette skyldes blandt andet, at bøn ofte indeholder ideer om det moralske gode, det dydige menneske og den rette livsførelse. Samtidig kan bønnen være en afgørende metode til at efterleve disse idealer - såsom i hesykasmen, hvor jeg vil påstå, at bønnen udgør tyngdepunktet for den bedendes etiske liv.

\section{Bøn som et af etikkens tyngdepunkter}

Lad mig for at underbygge min pointe kort give to andre eksempler på tænkningstraditioner, hvor bøn ligeledes kan ses som hovednerve for individets etiske liv.

I zarathustrismen bruges bøn blandt andet som en selvpåmindelse om at påtage sig ansvar for at opmuntre og udleve det gode gennem gode tanker, gode ord og gode handlinger. Bønnen er altså ikke, som den fra ateistisk side lejlighedsvis beskyldes for at være, en passiv anmodning om intervention baseret på en ansvarsfralæggende tilskrivning af alle kausalforbindelser til højere, transcendente magter. Tværtom kan den zarathustrianske bønspraksis ses som grundsten i en selvinitieret karakterudvikling - eller etisk subjektformation i foucauldiansk terminologi.

Vender vi os mod de græske stoikere, fremtræder bønnen ligeledes som selvets instrument til aktivt at handle på egen livudfoldelse, en slags individets selvoprustning. Dette ses eksempelvis i Marcus Aurelius' Meditationer, hvor den stoiske kejser blandt andet reflekterer over forholdet mellem skæbne, frihed, moralsk udvikling og bøn. En af kejserens slutninger er, at det at bede kan ses som 
et samarbejde med de højere kræfter, hvor individet påtager sig et ansvar for sin egen moralske udvikling (Aurelius 2014:bog 12.14). Bønnen fungerer i kejserens optik som en indtrængende påmindelse til selvet om dets tilstræbte værdier og dyder; en bevidstgørende artikulation af de idealer, et individ sætter for egen udvikling, og den etiske adfærd, individet forsøger at efterleve (op.cit.bog 9.40).

Hermed er den stoiske og zarathustrianske bønsform beslægtet med den hesykastiske, idet påkaldelsen af det hellige gennem bøn i alle tre tænkningstraditioner kan fortolkes som en anmodning fra den bedende om støtte, styrke og indsigt til at ændre sin karakter. Bønnen kan siges at være en samtale med subjektets eget, fremtidige, bedre selv, et selv, der bliver synligt for den bedende gennem Guds hjælp. Nærmere betegnet er bønnen en dialogisk selverkendelse muliggjort og medieret af en ekstern kraft. Fælles for de tre traditioner er bønnens rolle som brændende tyngdepunkt for individets etiske liv og udvikling. Som en teknolo-

gi til at skabe selvindsigt og udvikling hjælper bønnen den bedende til at antage nye, ,bedre“ former og legemliggøre idealer om det gode.

I hesykasmen er den personlige oplevelse af guddommeliggørelse i sig selv et endepunkt for den bedendes bestræbelse. Samtidig tjener denne transformationen et efterfølgende formål, der rækker ud over den bedende. At fjerne sig fra verden $\mathrm{g}$ andre ses som en nødvendig betingelse for at påbegynde åndelig udvikling i hesykasmen, men tilbagevenden for at hjælpe næsten til dennes rejse mod theosis præsenteres som den yderste dyd (Horujy 2019:57). Først når den enkelte har vendt sig mod sig selv og kultiveret hesychia samt ren kærlighed til Gud, kan hun elske næsten ubetinget og uselvisk (Ware 2004). Kærlighed til Gud og næsten ses derfor som gensidigt skabende i hesykasmen (se eksempelvis Maximos Bekenderen:54).

Dette forhold, at den hesykastiske bønspraksis på trods af sin karakter som et individuelt og introspektivt foretagende har et klart socialt sigte og udkomme, synes vigtigt at påpege for videre antropologisk undersøgelse af bønnen som etisk praksis. En dybere forståelse af bønnens etiske dimensioner bør ikke kun bero på det aktuelle, personlige rum omkring bønnen, men tillige inkorporere praksissens bredere mellemmenneskelige effekter.

\section{Noter}

1. Min udlægning af hesykasmen baserer sig primært på tekster af St Isaiah den Ensomme, Maximos Bekenderen, Munken Nikiphoros, Evagrius Eneboeren samt Gregory Palamas (se litteraturliste).

2. Opblomstringen skyldtes blandt andet udgivelsen af en russisk oversættelse af Philokalien i 1877 (Louth 2011:445-47) samt en stigende folkelig interesse for den russiskortodokse klostertilværelse og staretsinstitution (hvor særligt erfarne og ældre munke agerer åndelig vejleder 
for opsøgende). Epicenteret for interessen var Optina-Pustynj-klosteret beliggende $300 \mathrm{~km}$ sydvest for Moskva, hvor folkekære intellektuelle såsom Leo Tolstoj, Fjodor Dostojevskij, Ivan Turgenev, Nikolai Gogol og Vladimir Solovjov tog på åndelig retræte, lærte om de hesykastiske doktriner og hentede inspiration til deres værker (se eksempelvis Dostojevskijs karakter Fader Zosima i Brødrene Karamazov for en fremragende portrættering af en hesykastisk starets) (Gavrilyuk 2013:492; Gavrilkin 2011:449-50; Johnson 2010:36-39; Kornblatt 2009:18).

3. I dag forbindes jesusbønnen ikke alene med hesykasmen. Bønnen er meget anvendt på tværs af kristne kirkesamfund og anses derfor som en økumenisk bøn. Hos den nyetablerede åndelige trospraksis Christfulness på Frederiksberg benyttes jesusbønnen eksempelvis som mantra under 20 minutters guidede mindfulnessmeditationer, der har til formål at påskønne selvudvikling $\mathrm{i}$ den enkelte gennem meditativ bøn (Madsen 2012).

4. Se desuden Luhrmann (2018) for en mere dybdegående analyse af bøn som metakognitiv praksis.

5. For en mere udførlig diskussion af forholdet mellem selvskabelse og selvtranscendens, se Hadot (2015 [1995]), Faubion (2013) samt Marie (2021).

\section{Litteratur}

Asad, Talal

1993 Genealogies of Religion. Disciplines and Reasons of Power in Christianity and Islam. Baltimore: Johns Hopkins University Press.

Aurelius, Marcus

2014 Meditations. London: Penguin Books.

Bandak, Andreas

2017 The Social Life of Prayers. Introduction. Religion 47(1):1-18. https://doi.org/ 10.1080/0048721X.2016.1225904.

Demacopoulos, George E.

2013 Ch. 18: The Mystery of Divine/Human Communion in the Byzantine Tradition. In: J.A. Lamm (ed.): The Wiley-Blackwell Companion to Christian Mysticism. Pp. 267-81. Chichester: Blackwell Publishing Ltd.

Evagrius Eneboeren

345/6-399 On Prayer. 153 Texts. The Philokalia Vol. 1:53-72.

Faubion, James D.

2013 The Subject that is not One. On the Ethics of Mysticism. Anthropological Theory 13 (4):287-307. https://doi.org/10.1177/1463499613509991.

Foucault, Michel

1988 Technologies of the Self. In: L. Martin, H. Gutman \& P. Hutton (eds): Technologies of the Self. A Seminar with Michel Foucault. Amherst: University of Massachusetts Press.

1990 The Use of Pleasure. Volume 2 of the History of Sexuality. New York: Vintage Books.

1997 Ethics. Subjectivity and Truth. Vol. 1. Ed. Paul Rabinow. New York: The New Press.

Gavrilkin, Konstantin

2011 Way of the Pilgrim. In: J.A. McGuckin (ed.): The Encyclopedia of Eastern Orthodox Christianity. Vol. I. Pp. 449-50. Malden: Wiley-Blackwell. 
Gavrilyuk, Paul L.

2013 Ch. 32: Nineteenth- to Twentieth-Century Russian Mysticism. In: J.A. Lamm (ed.): The Wiley-Blackwell Companion to Christian Mysticism. Pp. 489-500. Chichester: Blackwell Publishing Ltd.

Gregory Palamas

1296-1359 Three Texts on Prayer and Purity of Heart. Philokalia Vol. 4:343-446.

Hadot, Pierre

2015 [1995] Philosophy as a Way of Life. Spiritual Exercises from Socrates to Foucault. Singapore: Blackwell Publishing.

Henkel, Heiko

2005 Between Belief and Unbelief Lies the Performance of Salât. Meaning and Efficacy of a Muslim Ritual. The Journal of the Royal Anthropological Institute 11(3):487507. https://doi.org/10.1111/j.1467-9655.2005.00247.x.

Horujy, Sergey S.

2019 The Two Sorts of Hesychast Ethics. Russian Studies in Philosophy 57(1):40-69. https://doi.org/10.1080/10611967.2019.1545974.

Isaiah den Ensomme

489/91 On Guarding the Intellect. Twenty-Seven Texts. Philokalia Vol. 1:21-28.

Johnson, D.L. Christopher

2010 The Globalization of Hesychasm and the Jesus Prayer. Contesting Contemplation. London: A\&C Black.

Kornblatt, Judith Deutsch

2009 Divine Sophia: The Wisdom Writings of Vladimir Solovyov. Ithaca: Cornell University Press.

Louth, Andrew

2011 Philokalia. In: J.A. McGuckin (ed.): The Encyclopedia of Eastern Orthodox Christianity. Vol. I. Pp. 445-47. Malden: Wiley-Blackwell.

Luehrmann, Sonja

2017 Praying with the Senses. Contemporary Orthodox Christian Spirituality in Practice. Bloomington: Indiana University Press.

Luhrmann, Tanya M.

2018 Prayer as a Metacognitive Activity. In: J. Proust \& M. Fortier (eds): Metacognitive Diversity. An Interdisciplinary Approach. Oxford University Press.

Madsen, Ole Skjerbæk

2012 Christfulness. Frederiksberg: Areopagos Forlag.

Mahmood, Saba

2001 Rehearsed Spontaneity and the Conventionality of Ritual: Disciplines of "Salât". American Ethnologist 28(4):827-53. https://doi.org/10.1525/ae.2001.28.4.827.

2005 Politics of Piety. The Islamic Revival and the Feminist Subject. Princeton: Princeton University Press.

Marie, Sidsel

2021 Hesychastic Practices of and beyond the Self. The Ethical Aspects of SelfTransformation. Pan-Sophia 4:106-39. 
Maximos Bekenderen

1st century Four Hundred Texts on Love. Philokalia Vol. 2:53-100.

Meyendorff, Jean \& John Meyendorff

1974 Byzantine Hesychasm. Historical, Theological and Social Problems. London: Variorum Reprints.

Munken Nikiphoros

13th century On Watchfulness and the Guarding of the Heart. Philokalia Vol. 4:192-206.

Naumescu, Vlad

2012 Learning the "Science of Feelings". Religious Training on Eastern

Christian Monasticism. Ethnos 77(2):227-51. https://doi.org/10.1080/

00141844.2011.595809.

Payne, Daniel P.

2011 The Revival of Political Hesychasm in Contemporary Orthodox Thought. The Political Hesychasm of John Romanides and Christis Yannaras. Lanham, MD:

Rowman and Littlefield.

Petcu, Liviu

2016 The Reception of Hesychasm in the Romanian Culture. International Journal of Orthodox Theology 7(1):62-84.

Robbins, Joel

2004 Becoming Sinners. Christianity + Moral Torment in a Papua New Guinea Society. Berkeley: University of California Press.

Strezova, Anita

2014 Hesychasm and Art. The Appearance of New Iconographic Trends in Byzantine and Slavic Lands in the 14th and 15th Centuries. Canberra: ANU Press.

Ware, Kallistos

1986 [1979] The Orthodox Way. Crestwood: St. Vladimir's Seminary Press.

2004 Seek First the Kingdom. Orthodox Monasticism and Its Service to the World. Theology Today 61:14-25.

2011 Hesychasm. In: J.A. McGuckin (ed.): The Encyclopedia of Eastern Orthodox Christianity. Vol. I. Pp. 299-306. Malden: Wiley-Blackwell. 